tion how the migratory instinct became established in certain members of the family, when it appears not to be physiologically indispensable to them. At the period of migration, when the smolts are fit to go to the sea, they evince, I believe, the utmost restlessness (like all migratory animals), and frequently leap out of the fresh water in which they are confined, and die on the banks. This has taken place year after year in the nursery ponds on the Plenty River, Tasmania, where it was first placed beyond question that a migratory salmonid could remain and breed perfectly freely year after year in fresh water. On January 20, I866, Mr. J. A. Youl, C.M.G., sent out to Tasmania a consignment of salmon, salmon-trout, and brown trout (S. fario Ansonii). On June 25, 1869 , several parrs of the salmon-trout, then weighing in some instances more than a pound, were busy nesting, the result being that many thousands of fry from their ova were subsequently sent to stock other rivers. The imprisoned salmon-trout have continued to breed for several years in succession, but there has been noticed in them a tendency to become sterile as they grow older. There is also some reason to believe that Salmo salar has bred in the ponds on the Plenty. Two young specimens which, from certain circumstances, the Commissioners believed to be true salmon, were sent to Dr. Gïnther for examination, with full information as to their origin and history; and he, while expressing his reluctance to give a decided opinion, stated that they "presented all the anatomical characters of $S$. salar." Full details of the breeding in fresh water of $S$. trutta will be found in "The Acclimatisation of the Salmonidæe at the Antipodes-its History and Results."

ARTHUR NICOLS

\section{A Sea Monster}

A FRIEND of mine, Capt. W. Hopkins, of the schooner Mary Ogilvie, who has just returned from a voyage all round Australia, has given me the following information, which I forward you for publication, not so much because of its interesting character, but in order that other travellers may throw some light upon the character of the animal, which, if an Octopus, must be of much larger dimensions than those usually met with. On June 15 , when in S. lat. $21^{\circ} 37^{\prime}$ and E. long. $113^{\circ} 49^{\prime}$, about five miles off the Exmouth Gulf on the western coast of the continent, he saw an immense creature which he took to be a species of Octopus. His attention was drawn to it by a perfect cloud of sea birds, and at first he naturally thought it must be a dead carcass, On approaching it, however, he found it was alive, and sluggishly disporting itself. In shape it was like a violin, but of immense size, with some six feelers about the greater diameters of the violin. It lay almost flat upon the water, was of a dark gray above and lighter gray below, and was continually elevating one of its feelers, apparently twice the thickness of a man's arm, to a height of from six to eight feet. It appeared to be vomiting, and as the birds were evidently feeding, that accounted for their presence in such numbers. Its size was so great that, had it grasped the vessel, it could easily have capsized it. The captain therefore got out of the way as quickly as possible, and without making definite measurements; but a large whale in the vicinity looked quite diminutive. It is a pity that something more exact as to size is not available, but I think the description is sufficient to convey an idea of the nature of the monster. All along the northern and western coasts of the continent vast shoals of pumice, in portions varying in size from ordinary gravel to about a foot in diameter, and completely covered with barnacles, were passed through.

Sydney, N.S.W., August 4

ALFRED MORRIS

\section{Hail}

WILL any of your readers kindly oblige me with particulars of the formation of a hailstone, and the effect produced upon it by falling through the air. How does it become frozen ? increase in size? and what are the conditions for its increase? up to what point in its passage does it increase? what cffect has temperature upon it in its downward career? after a certain point in its fall should it not theoretically decrease in size ? does it do so actually? how is it that larger stones generally fall in tropical or hot climates during thunderstorms than we witness during our English winters? Does a raindrop increase in size as it nears the earth? If so, please give reasons.

A. D.

Lisbon, September I

[The best account of the formation of hail is given in Ferrel's
"Meteorological Researches for the Use of the Coast Pilot," Part II. p. 85, a brief résumé of which is given in the "Encyclopædia Britannica," article Meteorology, p. I32.-ED.]

\section{THE " COMMA-SHAPED BACILLUS, ALLEGED TO BE THE CAUSE OF CHOLERA ${ }^{1}$}

WITH a view of studying the phase which the cholera question has now entered upon, in consequence of the publication of the results of the investigations of the German Cholera Commission in Egypt and India, I availed myself of the opportunity which the present vacation at the Army Medical School afforded of proceeding to Marseilles, where the disease has been prevalent since the end of June. Sir Joseph Fayrer was so kind as to enlist for me the valuable assistance of Dr. Le Roy de Méricourt, Médecin en Chef of the French Navy, who in various ways did his utmost to further my wishes. Dr. Marroin, the Chief of the Sanitary Department in Marseilles, was so good as to introduce me to the authorities of the Pharo Hospital, where the cholera cases are treated, and where, with the permission of the principal medical officer, Dr. Trastour, I was able to renew my acquaintance with the disease, and to collect material for studying afresh the microscopy of the intestinal discharges.

Before, however, referring to the results of my own observations, it will be convenient to epitomise the published history of the German Commission ; to point out the salient features of the results of their investigations in Egypt and in India ; and to make a few brief comments on such of the circumstances and conclusions as appear to call for notice. Shortly after the arrival of the Commission in Egypt, Dr. Robert Koch reported, on behalf of himself and his colleagues, that no special micro-parasites had been discovered in the blood, the lungs, the spleen, the kidneys, or in the liver in cholera, but that the intestinal mucous membrane was permeated by certain Bacilli which nearly resembled in size and form the Bacilli found in glanders. As is well known, these Bacilli are straight, and are, in fact, uncommonly like the ordinary microphytes associated with decay. Dr. Koch also states in connection with this subject that he had, previous to proceeding to Egypt, found similar Bacilli in the intestinal mucous membrane of four natives of India, but that he had then looked upon them as due to merely post mortem changes. When he came to Egypt, however, and found these same Bacilli in the intestines of perfectly fresh cases, he felt that an important link was furnished towards establishing the identity of the disease in Egypt with Indian cholera.

It is highly probable that the specimens from India which Dr. Koch had examined were those which were sent, at the request of the Imperial Health Department in Berlin, by the Sanitary Commissioner with the Government of India. These consisted of numerous dry coverglass specimens of blood which I had collected from several cholera patients, and of portions of the viscera of four natives who had died of the disease. All these were examined by me before they were despatched, and portions of each were reserved for further study. I had heard nothing further of them, but the publication of the remarks above referred to in Dr. Koch's Report of September 17, 1883, from Alexandria, recalled them to my mind, and I was glad to infer that my own negative results had been confirmed in Berlin. As already observed, no importance had been originally attached to the organisms which wcre present in the intestinal mucosa. During the last six months I have examined hundreds of stained microtome-sections of these four, and of other specimens of cholera intestines in my possession, and have found that, when the mucosa is infiltrated with

I A Memorandum by Surgeon-Major Timothy Richards Lewis, M.P., the Director-General, Army Medical Department. 
microphytes at all, they are either Micrococci, Bacteria, or long-oval, and straight Bacilli.

In the Report of the Commission, dated Calcutta, February 2, 1884, Dr. Koch, however, announces for the first time that the specific Bacillus of cholera is curved or comma-shaped, and not straight; so that apparently it had become necessary to abandon the microbe first fixed upon. Assuming that the four specimens from natives of India which had been examined by Dr. Koch were those which passed through my hands, the evidence they furnish seems to be in accordance with this view, as in not one of them have I been able to detect any invasion by unmistakable "commas," though at least one of the specimens may fairly be characterised as abundantly infiltrated (in the manner described by Dr. Koch) by straight (and as I prefer to call them) putrcfactive Bacilli. Judging from my own experience, therefore, any extensive infiltration of the intestinal mucous membrane in cholera by comma-shaped Bacilli must be exceedingly rarc; and this, I believe, is likewise the experience of the members of the late French Cholera Commission, MM. Straus, Roux, and Nocard, whose acquaintance I had the pleasure of making at M. Pasteur's laboratory on my return through Paris.

Whilst at Marseilles I had, as already stated, opportunities of observing numerous specimens of choleraic excreta, and found that comma-shaped Bacilli were, more or less conspicuously, present in all of them, though in some instances more than one slide had to be exanincd before any could be satisfactorily detected. It may also be mentioned that some of the discharges in which these org inisms were present manifested an acid reaction when tested with litmus paper. As Dr. Koch himself remarks, the proportion which the comma-shaped Bacilli bear to other organisms in the dejecta varies greatly. In some instances only one or two specimens are to be found in the field of the microscope, while in others they are very numerous, and Drs. Nicati and Rietsch (who are at present engaged in the study of the disease at Marseilles) were so kind as to show me a specimen of choleraic material they had obtained from the small intestine, in which the "commas" existed almost to the exclusion of all other organisms. This is a condition, however, which, I understand, is exccedingly rare. On the other hand, I have seen samples of choleraic dejecta in which totally different organisms prevailed to a like exclusion of others; and in one instance at Marseilles spirilla of various sizes and forms were the most conspicuous of the microorganisms present. So far, therefore, the selection of the comma-shaped Bacilli as the materies morbi of cholera appears to be entirely arbitrary.

Dr. Koch and his colleagues have adduced no evidence to show that they are more pernicious than any other microbe ; indeed, as a matter of fact, the sole argument of any weight which has been brought forward in favour of the comma-shaped Bacillus being the cause of cholera, is the circumstance that it is more or less prevalent in every case of the disease, and that the German Commission had not succeeded in finding it in any other. With regard to the suggestion that the cholera process may in some way favour the growth of these Bacilli, and that these are not necessarily the cause of the disease, Dr. Koch remarks, in the Report from Calcutta above cited, that such a view is untenable, inasmuch as it would have
to be assumed "that the alimentary canal of a person stricken with cholera must have already contained these particular Bacteria; and, seeing that they have invariably been found in a comparatively large number of cases of the disease both in Egypt and India - two wholly separate countries-it would be necessary to assume, further, that every individual must harbour them in his system. This, however, cannot be the case, because, as already stated, the comma-like Bacilli are never found except in cases of cholera."
Had Dr. Koch and his colleagues submitted the secretions of the mouth and fauces - the very commencement of the alimentary canal-to a careful microscopic examination of the same kind as that to which they have submitted the alvine discharges, I feel persuaded that such a sentence as the foregoing would not have becn written, seeing that comma-like Bacilli, identical in size, form, and in their reaction with aniline dyes, with those found in choleraic dejecta, are ordinarily present in the mouth of perfectly healthy persons. ${ }^{1}$

There is no difficulty in putting this statement to the test; and to any one acquainted with the methods ordinarily adopted for staining and mounting fungal organisms of this character, no special directions need be given. The procedure followed by me to demonstrate these "commas" in the saliva is precisely that adopted for finding them in the dejections. A little saliva should be placed on a cover-glass (preferably in the morning
before the teeth are brushed) and allowed to dry thoroughly, either spontaneously or aided by a gentle heat. The dry films thus obtained should be floated for a minute or two with one or other of the ordinary solutions of aniline dyes adopted for such purposes, such, for example, as fuchsine, gentian-violet, or methylene blue. The cover should then be gently rinsed with distilled water, and the film re-dried thoroughly. The preparation may now be mounted in dammar varnish or Canada balsam dissolved in benzol, and should be examined under a I/I2th or I/I6th of an inch oil-immersion lens.

As in choleraic discharges so in the saliva the number of comma-shaped Bacilli will be found to vary greatly in different persons, and at different times in the same person. Sometimes only one or two "commas" will be seen in the field, at others a dozen may be counted, and, occasionally, little colony-groups of them may be found scattered here and there throughout the slide.

It may be remarked in passing, and as bearing upon what has been already said regarding the general absence of comma-shaped Bacteria from the intestinal mucosa itself, that they do not appear to manifest any special tendency for attacking the decaying epithelial scales of the mouth, but that, on the contrary, they are for the most

I Since this Memorandum was submitted, I have observed that Dr. Koch states, in his recent address on the subject, that, after his return to Berlin he had examined, amongst other things, the secretions of the mouth for commashaped Bacill, but had found none; and, further, that he had consulted
persons of much experience in bacterial researches as to whether they had persons of much experience in bacterial researches as to
ever seen such organisms, and was told that they had not.

It may be of assistance to future observers if I give the dimensions of half-
It seen such organisms, and was told that they had not. It may be of assistance to future observers if I give the dimensions of half-
a-dozen comma-shaped Bacilli as found in each of the following:- $-(a)$ In the a-dozen comma-shaped Bacilli as found in each of the following:- $-(a)$ In the
alvine discharges of three cholera-affected persons ; $(b)$ in the small intestine alvine discharges of three cholera-affected persons; $(b)$ in the small intestine
of a person who had died of the disease and in whom they existed almost to of a person who had died of the disease and in whom they existed almost to
the exclusion of other organisms; $(c)$ in a cultivation of them in Agar-Agar
jelly; and $(d)$ in the secretions of the mouth of three healthy persons, ranging jelly; and $(d)$ in the secretions of the mouth of three healthy persons, ranging
from four to fifty years of age. The measurements were made (with the valuable assistance of $\mathrm{Mr}$. Arthur E. Brown, B.Sc. Lond.) under a magnifying power of rooo diameters - a Powell and Lealand's $\mathrm{t} / \mathrm{I}$ th th of an inch oilimmersion lens, with a wide angle condenser, being used.

Lengrh and Width (in Micro-millimetres *) of Comma-shaped Bacilli in Choleraic Matérial

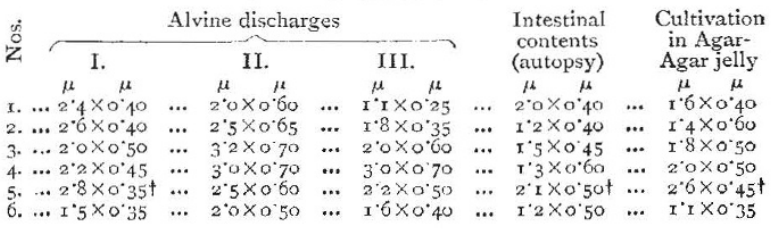

Jengtri and Width (IN Mrcro-millimetres*) OF Comma-shal'ed Bacili. in Secretions of the Mouth in Health

$$
\begin{aligned}
& \text { Nos. } \quad \text { I. } \mu \text { II. } \mu \quad \text { IIJ. }
\end{aligned}
$$

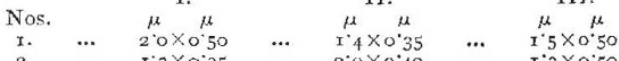

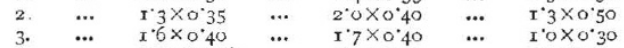

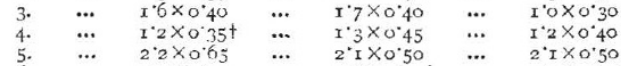

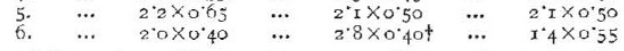

$$
\begin{aligned}
& \text { * One micro-millimetre }(n)=\text { ' nor millimetre }\left(=\mathrm{r} / 25, \mathrm{OOo}^{\prime \prime}\right) \text {. } \\
& \text { t } s \text {-sliaped comma-barilli. }
\end{aligned}
$$


part found free in the fluid, the epithelium being studded with other bacterial forms.

Persons who have not been in the habit of examining dried saliva-films will probably be surprised at the number and variety of the organisms which are, more or less, constantly to be found in the mouth; and especially at the number of spirilla with which the fluid is generally crowded.

The alvine discharges in cholera sometimes swarm with precisely similar spiral organisms, and, indeed, as has long been known, the fluid exuded into the intestines in this disease is peculiarly suitable for the growth of these and allied microbes. But, so far as my own experiencedating from 1869 - of the microscopic examination of such a fluid goes, all the microphytes ordinarily found in it are likewise to be found, to a greater or less extent, in the secretions of the mouth and fauces of unaffected persons. And with reference to the comma-like Bacilli found in cholera, to which such virulent properties have been ascribed, I shall continue to regard them as identical in their nature with those ordinarily present in the saliva until it has been clearly demonstrated that they are physiodogically different.

Pathological Laboratory, Netley, September I

\section{FORESTS IN COBURG, GERMANY, AND RUSSIA}

A BLUE-BOOK under the title of "Reports by Her A Majesty's Representatives abroad on the Cultivation of Woods and Forests in the Countries in which they reside," has just been published by Messrs. Harrison \& Sons. These Reports are of an extremely interesting character, and we gladly draw attention to them, appearing as they do at an opportune moment before the close of the Forestry Exhibition at Edinburgh.

The Reports come from Coburg and Gotha, Germany, Norway, Russia, and Sweden, and in the form of an appendix is a précis by Dr. Lyons, M.P., of the Reports on Forestry of the United States Department of Agriculture. In each one of these Reports much valuable information is given and information of a very varied character. Thus in the first we are told that the forests in Gotha consist of 85 per cent. of pine and 15 per cent. of other wood. The principal timber-trees are pine and beech, whereas the remaining sorts of wood, namely Scotch fir, spruce, larch, oak, maple, ash, birch, and elm are found only in small quantities or mixed with the other species. The period during which the different woods are gradually brought into use is such that pine forests and mixed forests shall yield as large an amount as possible of saleable timber, whilst in the beech woods the greatest amount of wood as fuel is sought without allowing the trees to attain an age at which they would no longer pay the interest on the value of the soil. Pine and beech wood in higher situations are, according to these principles, usually cultivated and worked in cycles of one hundred years, while spruce on the lower heights and in the plains are worked on an eighty ycars' cycle. The woods for protection on the high grounds are subject to especial treatment, as no clear fellings take place, and care is taken to leave standing groups of foliage trees equally distributed over the whole surface. The usual rules followed are : early felling of the trees in a cycle of eighty years, leaving occasional large shelter trees, and utilising the undergrowth for purposes of renewal. The administration of the Domain forests in the Duchy of Coburg is carried on on scientific principles, and consists of regular felling at stated periods over certain areas; pine timber trees are usually cut every ninety years, while oak, ash, beech, birch, \&c., are not cut till after 120 years' growth.

The Report on the general administration of Prussian
State Forests treats of their organisation, expenditure, and results, and points to the desirability of introducing others than indigenous trees into the forests. On the subject of education in forestry it is stated that the School of Forestry at Eberswalde completed in June I 880 the fiftieth year of its existence, and had at that period in all nearly 1600 pupils. There is also a School of Forestry at Münden, and the half-yearly attendance at both schools showed in 1878 an average of 148 pupils, whereas in 1880 the number had increased to 210 . The attendance was therefore largely on the increase, and it was then proposed to give voluntary education in these matters to the "Jäger Bataillonen" of the army. This plan has, according to latest accounts, been attended with so much success that the education has become obligatory, and forms a regular portion of their service.

From Russia a very elaborate Report treats, amongst other things, of the various kinds of trees found in Russia, with notes on their distribution, and some interesting facts on the consumption of wood and the uses to which it is put, showing that house and ship building consume a very large proportion, and that the minor industrics when put together form a not unimportant total. After showing the extensive destruction of forests that has been going on in different parts of Russia for some years past, the Report considers the question of plantations along railways, the object of which is to protect the track from snowdrifts, and a list of the best trees and shrubs for this purpose is given. (n the subject of tree-planting on the steppes of South Russia, it is stated that Count Kisseleff, when travelling through several provinces in I840 found, much to his surprise, amongst the German colonists not only good kitchen gardens but also flourishing plantations of forest trees. The colonists had been obliged on every plot of land to plant a certain number of trees. The first experiences, however, were so severe that many of the colonists preferred to return to Germany ; those that remained were forced to plant their allotments with trees which, with infinite trouble, they succeeded in doing, and these plantations are now a great ornament to the steppes, and from a climatic as well as an agricultural point of view have been of great importance to the colonists, and have laid the foundation of the planting which is now carried out on the steppes in a scientific manner. A forestry school was established, but closed in 1866 , and the allowances for planting which had been granted were reduced to a minimum. Since that, however, matters have been put on a more satisfactory footing, and planting is conducted in a systematic manner.

\section{STONE HATCHETS IN CHINA}

ITTLE has yet been done to illustrate the Stone Age $\mathrm{L}$ in China, and this is very likely to be true for some time to come from the fact that the pcople of the country worked in metals four thousand years ago.

To begin with the Han dynasty, B.C. 206 to A.D. 220 , one chief source of revenue was iron in those days, and Shansi had grown rich and powerful because of her iron foundries. The correct Confucianists objected to the spirit of gain-seeking which they saw showing itself in the expansion of trade. In the reign of Chauti, B.c. 8o, a book was written on the salt and iron duties, which was a record of the views then maintained by the purists of the Confucian school in contrast with those of the political economists of that day. The advantages of the encouragement of trade were detailed in full, and the sympathy of the modern reader goes with the economists, who saw that the strength and prosperity of the country must be increased by developing her resources. The country was then old, and the stone hatchet period must be sought much earlier. The same state of things existed in the time of Kwan chung, B.C. 700 . Living before Confucius, 